\title{
Prototype Matching of Personality Disorders with the Dimensional Clinical Personality Inventory
}

\author{
Lucas de Francisco Carvalho ${ }^{1}$ \\ Ricardo Primi \\ Universidade São Francisco
}

\begin{abstract}
This study aimed to investigate validity evidence of the Dimensional Clinical Personality Inventory (IDCP) through the expected associations with the five-factor model (FFM), especially in regard to the prototype matching of personality disorders. A non-clinical sample ( $N=94)$, aged between 19 and 55 years $(M=25.5 ; S D=7.35)$, and 59.6\% male, answered the IDCP and the NEO-PI-R for the assessment of 12 dimensions related to personality disorders and evaluation of five personality dimensions, respectively. The results pointed to consistent empirical relations between the dimensions of the IDCP and the NEO-PI-R, as well as between the diagnostic categories of DSM-IV-TR based on the FFM and the IDCP dimensions.
\end{abstract}

Keywords: personality disorders, personality traits, personality measures, psychometrics

\section{Correspondência Prototípica dos Transtornos da Personalidade com o Inventário Dimensional Clínico da Personalidade}

\begin{abstract}
RESUMO - O objetivo deste estudo foi investigar evidências de validade para o Inventário Dimensional Clínico da Personalidade (IDCP) por meio de associações esperadas com o modelo dos cinco grandes fatores (FFM), especialmente no que se refere à correspondência de protótipos dos transtornos da personalidade. A amostra, não clínica $(N=94)$, com idade variando entre 19 e 55 anos $(M=25,5 ; D P=7,35)$, sendo $59,6 \%$ do sexo masculino, respondeu o IDCP e o NEO-PI-R para avaliação de doze dimensões relacionadas aos transtornos da personalidade e de cinco dimensões da personalidade, respectivamente. Os resultados apontaram para relações empíricas coerentes entre as dimensões do IDCP e as dimensões do NEO-PI-R, bem como entre as categorias diagnósticas do DSM-IV-TR com base no FFM e as dimensões do IDCP.
\end{abstract}

Palavras-chave: distúrbios da personalidade, traços de personalidade, medidas da personalidade, psicometria

In the last decade several studies on personality disorders were performed, a phenomenon that has increased due to the period of pre- and post- release of the fifth edition of the Diagnostic and Statistical Manual of Mental Disorders (DSM-5; 2013; see, Krueger \& Eaton, 2010; Pilkonis, Hallquist, Morse, \& Stepp, 2011; Skodol, Bender, Oldham, et al., 2011; Skodol, Bender, Morey, et al., 2011). From these studies, the DSM-5 Task Force, responsible for personality disorders (Skodol, Clark, et al., 2011) proposed that these disorders represent the failure to develop a sense of selfidentity and the capacity for interpersonal functioning that are adaptive in the context of the individual's cultural norms and expectations.

According to this definition, personality disorders may be assessed and diagnosed from different models. There are basically two groups that encompass great part of the proposed models, which are: the categorical and dimensional models (eg., Widiger \& Trull, 2007). Additionally, considering characteristics of these models, the prototypic model was proposed (Ortigo, Bradley, \& Westen, 2010).

Categorical models are formed by sets of symptoms in which a patient fits if he or she presents a minimal number

1 Endereço para correspondência: Programa de Pós-graduação em Psicologia da Universidade São Francisco, Rua Alexandre Rodrigues Barbosa, n. 45, Itatiba, SP, Brazil. CEP. 13251-040.E-mail. lucas@ labape.com.br of symptoms. For instance, for a patient to be diagnosed with borderline personality, it is necessary that he or she meet more than five of the nine criteria established for this disorder. Therefore, authors understand that this is a dichotomous diagnosis model, i.e., either the subject reaches a minimal number of criteria and is diagnosed with the disorder, or it is considered that the disorder is absent (Widiger \& Frances, 2002).

Differently, in a dimensional model for personality disorders, all individuals must be assessed according to several traits related to these disorders (Millon \& Davis, 1996). Therefore, these individuals are assessed in dimensions, representative of sets of traits regarded as basic for assessing personality disorders, in which each individual is assessed not only in certain characteristics, but in all of them (Primi, 2010).

Regarding the proposal for prototypical models, these are models that set off from categories composed by characteristics that usually manifest jointly, but none is characterized as a necessary pre-requisite (Ortigo et al., 2010). Then, the level of similarity of the person with these categories by means of continuous scales is verified, that is, the similarity of the person's profile and the typical profile (prototype) of people with certain disorders is checked, what is called prototypical correspondence or prototype matching (Widiger, Costa, \& McCrae, 2002). 
One of the models that consider the prototype matching is the model of the Big Five Factors, or Five Factor Model (FFM), which sets off from an essentially dimensional nature. The FFM has its origin in the field of study of healthy personality (Costa Jr. \& McCrae, 1992), but in recent decades it has also been inserted in the area of personality disorders (Rottman, Ahn, Sanislow, \& Kim, 2009; Samuel \& Widiger, 2008). From the empirical point of view, it is certainly one of the strongest proposals available in the area (Widiger, 2011).

Basically, the FFM proposes that personality should be understood by means of five dimensions, which are usually referred to as extraversion, agreeableness, (or socialization), conscientiousness (or realization), neuroticism (or emotional instability), and openness to experience (Costa Jr. \& McCrae, 1992). It is noteworthy that these five dimensions have recently been subdivided into 30 facets when evaluated by the NEO Personality Inventory Revised (NEO-PI-R; Costa Jr. \& McCrae, 2009), with six facets by dimension (Widiger, Trull, Clarkin, Sanderson, \& Costa, 2002).

According to Widiger and Lowe (2008), the proposal of using FFM for the assessment and diagnosis of personality disorders is mainly based on the dimensions and facets of the FFM, but also uses the nomenclature for personality disorders presented in DSM-IV-TR. From the perspective of prototypical correspondence, it is a procedure proposed by Widiger, Costa, et al. (2002) divided into four stages: assessment of the dimensions and facets, identifying problems/losses, level of clinical significance, and relationship between the person's profile and the prototypical profiles of personality disorders. It is in the last stage that the prototype matching is, in fact, performed.

In the first stage, the person is evaluated on the five dimensions of FFM and its facets. For this purpose, different tools can be used, such as the NEO-PI-R (Costa \& McCrae Jr., 2009) or the Five Factor Model Rating Form (FFMRF; Mullins-Sweatt, Jamerson, Samuel, Olson, \& Widiger, 2006). From this evaluation, the individual's personality trait levels are established. Based on these data, the second stage begins, which identifies the main areas of loss and difficulties in an individual's life.

The third stage establishes which difficulties and losses found in the previous stage have clinical significance. For this purpose, two criteria must be met: the individual's personality trait levels must reach a minimum cutoff point, and the difficulties should be considered severe. And finally, in stage four, the relationship between the profile found for the person and the diagnostic profiles of personality disorders is investigated. In this last stage, it is possible to find similar profiles to those proposed in the DSM-IV-TR, as well as unprecedented profiles, which have not been presented in the literature yet.

Furthermore, we must consider the correlation magnitudes found by Samuel and Widiger (2008) among the 10 diagnostic characteristics of DSM-IV-TR and the five dimensions of the FFM from a meta-analysis combining 16 empirical studies on a total of 18 independent samples. From the data obtained, it is possible to infer which personality traits are more related to which dimensions and facets according to the FFM. According to data presented by the authors, in a broad perspective, the neuroticism dimension showed the highest (and all positive) magnitudes with the diagnostic categories, and the dimension openness to experience did not present any correlation higher than 0.15 . The diagnostic categories with the highest correlations were borderline and paranoid, although for all categories at least one correlation with magnitude higher than or equal to 0.20 was demonstrated.

Specifically, the neuroticism dimension had correlation magnitudes between 0.10 and 0.54 , being the highest with borderline, avoidant, dependent, and paranoid categories, and the lowest with histrionic, narcissistic, antisocial, and obsessive categories. The magnitudes evidenced from the extroversion dimension were between 0.04 and -0.49 , and the highest were with avoidant, schizoid, and histrionic categories (all negative), and the lowest with antisocial and narcissistic (positive), and borderline and obsessive (negative) categories. In relation to the openness dimension, the magnitudes were between -0.03 and 0.15 , being respectively, with the dependent and histrionic categories. In relation to the agreeableness dimension, the highest magnitudes were with narcissistic, paranoid, and antisocial categories (negative) and the lowest with obsessive, avoidant (negative) and dependent (positive) categories, so that the magnitudes ranged from -0.05 and -0.37 . And finally, the conscientiousness dimension presented magnitudes ranging from -0.10 and -0.33 , the highest being with antisocial, borderline (negative), and obsessive (positive) categories, and the lowest with schizoid, narcissistic, paranoid, and histrionic (negative) categories. It can be observed that each of the four (five) dimensions of the FFM tends to present more significant correlation magnitudes with certain personality disorders (Samuel \& Widiger, 2008).

Also Samuel and Widiger (2008), seeking to improve the information presented, observed correlations between the same diagnostic categories and the facets of the FFM. It is noteworthy that both for the previous data and for those that will be presented subsequently in a summary, the correlations were based on multiple instruments to assess the dimensions of the FFM and for the diagnosis of personality disorders in DSM-IV-TR.

Regarding the correlations based on facets, it may be noted that the diagnostic categories relate differently depending on the characteristics evaluated. Most facets of the neuroticism dimension were positive (except for two cases with histrionic and narcissistic categories, and one with obsessive category), all above 0.30 with borderline, nearly all above 0.20 with paranoid, avoidant, and dependent and, in contrast, none higher than or equal to 0.20 with obsessive (Samuel \& Widiger, 2008).

The relationships found with the extroversion dimension facets indicate magnitudes above 0.20 with avoidant, schizoid, and histrionic categories, being negative with the first two and positive with the last; also, three facets had negative magnitude and above 0.25 with the schizotypal category. Facets of the openness dimension presented the lowest magnitudes, with the highest between the actions facet and the avoidant dimension $(\mathrm{r}=-0.20)$. Nearly all correlation magnitudes between the agreeableness facets and the diagnostic categories were negative, except for the relationships with the dependent and obsessive categories. The highest positive magnitudes evidenced were with the 
paranoid and narcissistic categories, and in opposition, there were no magnitudes above 0.20 with the histrionic, dependent, and obsessive categories. And regarding the conscientiousness dimension facets, the highest magnitudes were with the obsessive category, positive, and above 0.20 , being practically all others below this magnitude. The data found in the study are corroborated by other studies (Widiger, Costa, et al, 2002; Widiger \& Lowe, 2008).

These data can be used as a basis for the search for evidence of validity for instruments that assess these constructs, i.e., pathological personality traits (representing personality disorders). An example is the Dimensional Clinical Personality Inventory (IDCP; Carvalho \& Primi, 2011), which was developed based on Millon's theory (Millon \& Grossman, 2007a, 2007b) to represent the criteria for personality disorders in DSM-IV-TR (APA, 2003), in a dimensional perspective (Carvalho, 2011). It is a selfreport instrument consisting of 215 items distributed in 12 dimensions for assessing personality disorders. Table 1 shows the dimensions of the IDCP and the disorders that are theoretically more related to them are presented.

Each dimension of the IDCP tends to be more related to one or another personality disorder (see Carvalho, 2011), which is expected in a dimensional perspective considering that a pathological personality functioning is composed of several related dimensions (Schroeder, Wormworth, \& Livesley, 1992). However, this association was based on content analysis of the items that were grouped in the factors in relation to which criteria they represented in the DSM-IVTR (APA, 2003). This study seeks to go further, empirically testing the associations proposed by comparing the results of the IDCP with the profiles of the disorders in the NEOPI-R, which are already documented and present evidence of validity in the literature. We expect that the scales of the IDCP present higher magnitudes of correlation with the dimensions

Table 1.Relationships between the dimensions of the IDCP and personality disorders

\begin{tabular}{|c|c|}
\hline Dimensions & Personality Disorders \\
\hline 1.Dependency & $\begin{array}{c}\text { Dependent, Depressive, } \\
\text { Borderline }\end{array}$ \\
\hline 2.Aggressiveness & $\begin{array}{c}\text { Sadistic, Antisocial, } \\
\text { Negativistic }\end{array}$ \\
\hline 3.Mood Instability & $\begin{array}{c}\text { Borderline, Negativistic, } \\
\text { global pathological } \\
\text { functioning }\end{array}$ \\
\hline 4.Eccentricity & Schizotypal, Schizoid \\
\hline 5.Attention Seeking & Histrionic, Narcissistic \\
\hline 6.Distrust & Paranoid, Narcissistic \\
\hline 7.Grandiosity & Narcissistic \\
\hline 8.Isolation & Schizoid, Schizotypal \\
\hline 9.Criticism Avoidance & $\begin{array}{l}\text { Avoidant, Schizoid, } \\
\text { Schizotypal }\end{array}$ \\
\hline 10.Self-sacrifice & $\begin{array}{c}\text { Masochist, Depressive, } \\
\text { Dependent }\end{array}$ \\
\hline 11.Conscienciousness & Compulsive \\
\hline 12.Impulsiveness & Antisocial \\
\hline
\end{tabular}

and profiles derived from the NEO-PI-R of correspondent disorders. Thus, we aim to demonstrate the validity of the IDCP for assessing personality disorders. We also aim to demonstrate the administration of the prototype matching analysis, which is a procedure that aims to complement the traditional interpersonal analysis at the level of the scales. Furthermore, it also seeks to verify similarity between variables for the analysis of intrapersonal profiles, at the level of the people, and finding similarities between these profiles and the definition of diagnostic categories from an empirical procedure (Primi, 2010).

Specifically, we expected that the dimensions would present respectively higher magnitudes with personality disorders: Dependency $\mathrm{x}$ dependent personality disorder; Aggressiveness $x$ paranoid, antisocial, and narcissist personality disorder; Mood instability x borderline personality disorder; Eccentricity x schizotypal personality disorder; Attention Seeking $\mathrm{x}$ histrionic personality disorder; Distrust $\mathrm{x}$ paranoid personality disorder; Grandiosity x narcissistic personality disorder; Isolation x schizoid, schizotypal, and avoidant personality disorder; Criticism Avoidance $\mathrm{x}$ avoidant personality disorder; Self-sacrifice $\mathrm{x}$ dependent personality disorder; Conscientiousness x obsessive compulsive personality disorder; and Impulsiveness $\mathrm{x}$ antisocial personality disorder.

\section{Method}

\section{Participants}

We recruited 94 participants, with ages ranging from 19 to 55 years $(M=25.5 ; \mathrm{DP}=7.35)$, being $59.6 \%$ male. The majority $(\mathrm{N}=91)$ was enrolled in higher education and only three were in graduate school. Furthermore, only $2.2 \%(\mathrm{~N}=2)$ claimed to be under psychiatric treatment, but were not on use of any medicament. Thus, we may consider the sample as a primarily non-clinical sample. As inclusion criteria for the study, the participants had to be at least 18 years old.

\section{Instruments}

Two instruments were administered: The Clinical Dimensional Personality Inventory (IDCP; Inventário Dimensional Clínico da Personalidade - IDCP; Carvalho \& Primi, 2011) and the NEO-PI-R (Costa Jr. \& McCrae, 2009). The IDCP is a test for self-report assessment of personality according to Millon's theory and the characteristics described on Axis II of the DSM-IV-TR. As previously described, it is an inventory consisting of 215 items distributed in 12 dimensions: dependency, aggressiveness, mood instability, eccentricity, attention seeking, distrust, grandiosity, isolation, criticism avoidance, self-sacrifice, consciousness, and impulsiveness (Carvalho, 2011). The approximate time of administration was 30 minutes for the IDCP.

The Brazilian version of the NEO Personality Inventory Revised concerns the translation and adaption of the NEOPI-R (Costa Jr. \& McCrae, 1992), which is a self-report test 
consisting of 240 items, whose objective is the psychological assessment of personality in five dimensions (neuroticism, openness to experience, agreeableness, consciousness, and extroversion) and their respective facets. The time of administration of the instrument was of approximately 40 minutes.

Regarding the indices of reliability (Cronbach's $\alpha$ ) of the dimensions and the facet of the Brazilian version of the NEO-PI-R $(\mathrm{N}=1,320)$, all dimensions presented a coefficient equal to or greater than 0.85 (Costa Jr. \& McCrae, 2009); and regarding facets, although most have reached levels equal to or greater than 0.70 , some of them obtained indices between 0.61 and 0.69 (anxiety, embarrassment, assertiveness, enthusiasm, positive emotionality, aesthetics, feelings, altruism, modesty, competence, and effort for achievements), others between 0.51 and 0.59 (actions, values, honesty, altruism, and compliance), and others between 0.40 and 0.49 (sensitivity). It is noteworthy that the levels of internal consistency below 0.70 may bring some loss for the correlations observed with the facets of the NEO-PI-R, a fact that should be considered when observing these data.

\section{Study Design and Procedure}

The instruments were administered to the participants, and all received the Informed Consent Form (Protocol CAAE 0350.0.142.000-08), which included the study's objective and the dissemination of the results in accordance with ethical standards. Thus, only those who agreed to participate in the research procedures and who signed the informed consent were able to participate in this study. Data were collected in the classrooms of the Psychology course at a University in the countryside of the state of São Paulo - Brasil and the administration also took place in the classrooms. Furthermore, the researcher was always present during the administration of the instruments, so that possible doubts of the participants were clarified. Nonetheless, very few participants presented questions throughout the administration procedures.

There were two separate analyses, in both cases aiming to verify the relationship between the IDCP and data from the NEO-PI-R in previous studies, such as correlations between the IDCP scales scores and the dimensions and facets of the NEO-PI-R, and prototype matching analysis.

The prototype matching analysis was based on a profile similarity index. This index is given by the correlation between two intra-individual profiles. As shown above, there are (Samuel \& Widiger, 2008) literature reviews summarizing the correlations between the 30 facets of the NEO-PI-R with each diagnostic category (personality disorders) of the DSM-IV-TR (APA, 2003). The vector of correlations of the 30 facets with the categories indicate the prototypical profiles of scores on the NEO-PI-R that people with a high score on a given disorder would present. Based on this, one can calculate indices of profile similarity of a person who has answered the NEO-PI-R with the profiles of each disorder, i.e., we can calculate the correlation of the intra-individual profile with the prototype profiles of each disorder. These correlations indicate the similarity of the person's profile and the prototypical profiles, being possible to investigate to which disorders the person resembles the most. This is called prototype matching.

In this study, as all participants responded the NEOPI-R, we calculated 10 similarity indices for each person, one for each disorder, about which there was information available in the literature regarding the prototypical profile in the NEO-PI-R (paranoid, schizoid, schizotypal, antisocial, borderline, histrionic, narcissistic, avoidant, dependent, and obsessive). These indices indicate the similarity of the person's profile with the typical profile of people with certain disorders. Afterwards, we calculated the correlations of the dimensions of IDCP with the similarity indices. It was expected, therefore, that the scales that represent a determined disorder would have high correlation magnitudes with the similarity indices of the correspondent prototype. For instance, it is expected that there is correlation between the attention seeking dimension and the similarity index of the histrionic profile, indicating that people with higher scores on the dimension attention seeking of the IDCP also presented profiles more similar to the typical prototype of histrionic people as revealed by the NEO-PI-R.

This type of analysis corresponds to the fourth step of the model by Widiger, Costa, and McCrae (2002) and refers to the analysis of similarity of people and not only variables. It is noteworthy the closest nature of the categorical approach of classification based on similarity analysis of people, but given in a dimensional continuous variable, i.e., by correlation coefficients.

\section{Results and Discussion}

First we used Pearson's correlation in order to investigate the relations between the dimensions of the IDCP and the dimensions and facets of the NEO-PI-R. The data are presented in tables 2 and 3. Table 2 presents in bold the higher magnitudes found for each dimension of the IDCP in relation to the dimensions of the NEO-PI-R.

It can be observed that most of the highest positive magnitudes occurred between the dimensions of the IDCP and the neuroticism dimension of the NEO-PI-R. This finding was expected since the characteristics of the neuroticism dimension are frequently pointed out in the literature as indicative of pathological functioning of the personality. Examples are data evidenced by Samuel and Widiger (2008), in which the neuroticism dimension is the one that presents the highest number of correlations with magnitude higher than 0.20 with the diagnostic categories of the DSM-IVTR. It is noteworthy that this dimension presented greater correlation magnitude with the mood instability dimension of IDCP, what is consistent, since both of them deal with widespread psychological discomfort attributes. In contrast, this dimension did not present significant relation with the IDCP's dimensions attention seeking and consciousness, which may suggest that these dimensions' items tend to assess more healthy characteristics than pathological ones. Future studies should develop this question.

Likewise, much of the correlation magnitudes found between the dimensions of the IDCP and the NEO-PI-R were negative, which was also expected since the items 
that compose the dimensions of the IDCP were developed to assess the pathological pole of the personality, and the dimensions of the NEO-PI-R, except for neuroticism, are more related to the healthy pole (Widiger, Costa, et al., 2002).

Both correlations with neuroticism and those with other scales of the NEO-PI-R suggest evidence of validity for the dimensions of the IDCP, since they are in the theoretically expected direction (positive with neuroticism and negative with the other scales). Furthermore, the aggressiveness and impulsiveness dimensions presented negative correlation magnitude ( -0.60 and -0.48 , respectively) with the agreeableness dimension, which confers validity for the dimension of the IDCP, considering that aggressiveness assesses reactions in which the individual does not consider the other to get what he wants and impulsiveness is related to reactions of impulsiveness and recklessness towards himself and others. However, the agreeableness dimension is related, among other aspects, to altruism, compliance, and sensitivity to the other (Widiger, Costa, et al., 2002). Agreeableness also significantly correlated with other dimensions of the IDCP, namely: grandiosity, criticism avoidance, mistrust, isolation, dependency, and eccentricity. These dimensions have in common a tendency of the individual to express some kind of difficulty regarding the quality of the interpersonal relationships that he or she establishes with people, which is coherent with the correlation evidenced with the dimension of the IDCP (Costa Jr. \& McCrae, 2009).

On the other hand, the IDCP's attention seeking dimension showed higher positive relationship with the NEO-PI-R extraversion scale. This relationship was also expected since the dimension of the IDCP concerns the exaggerated attention seeking from others and intense search for friendships, and the extraversion dimension, in general, is related with the ability to relate to people, in order to establish interpersonal relationships (Costa Jr. \& McCrae, 2009). Differently, the extraversion dimension was negatively correlated with criticism avoidance and isolation (besides emotional instability), which is consistent as the three dimensions have an important (quantitative) decrease in interpersonal relationships as a backdrop.
Also, the IDCP conscientiousness dimension showed higher magnitude (positive) of correlation with the conscientiousness scale of the NEO-PI-R. This relationship was expected, considering that both are related to the need for order, organization, perfectionism, focus on duties, among others. This dimension of NEO-PI-R was negatively correlated with the impulsiveness, mood instability, addiction, aggression, and criticism avoidance dimensions, suggesting that people with high scores on these dimensions tend to have difficulties in organization and focus on duties. In general these relations are consistent, but some should be further analyzed, for instance, its relation with the criticism avoidance dimension.

It is also noteworthy that the openness dimension of the NEO-PI-R was the one with the lowest number of significant correlations, which was expected (Widiger, Costa, et al., 2002). Still, this dimension was significantly correlated with the attention seeking (positive) dimension, and criticism avoidance (negative). These relations should be further investigated in future studies.

Also, the relationships found in Table 3, among the facets of NEO-PI-R and the dimensions of IDCP, favor the validity of the interpretation performed by means of the scores obtained by respondents on the dimensions of the IDCP. We will emphasize the relationships that presented higher magnitudes. The dependency dimension was positively correlated with hostility, depression, and vulnerability facets and negatively with self-discipline. This suggests that people with high scores on the dimension of IDCP present, on the one hand, trend to experience anger, frustration, bitterness, and susceptibility to stress and psychological aggression, and on the other, little ability to begin tasks and carry them to an end (Widiger, Costa, et al., 2002). These interpretations corroborate the definition of the dependency dimension, which is related to the inability to make decisions and to build self-confidence.

The aggressiveness scale, which groups characteristics related to disregard to others and reckless and violent behavior, showed a positive relationship with the hostility facet and negative relationships with most facets of agreeableness, which was expected. These data suggest

Table 2. Correlations between dimensions of IDCP and the NEO-PI-R

\begin{tabular}{|c|c|c|c|c|c|}
\hline & Neuroticism & Extroversion & Openness & Agreeableness & Conscientiousness \\
\hline Dependency & $0.54 * *$ & -0.18 & -0.11 & $-0.22 *$ & $-0.31 * *$ \\
\hline Aggressiveness & $0.40 * *$ & -0.15 & -0.14 & $-0.60 * *$ & $-0.24 *$ \\
\hline Mood instability & $0.79 * *$ & $-0.36 * *$ & -0.08 & $-0.43 * *$ & $-0.33 * *$ \\
\hline Eccentricity & $0.29 * *$ & -0.19 & 0.04 & $-0.21 *$ & -0.04 \\
\hline Attention Seeking & -0.10 & $0.56 * *$ & $0.34 * *$ & -0.13 & 0.17 \\
\hline Distrust & $0.43 * *$ & -0.18 & -0.04 & $-0.31 * *$ & -0.01 \\
\hline Grandiosity & $0.51^{* *}$ & -0.16 & -0.09 & $-0.39 * *$ & -0.09 \\
\hline Isolation & $0.47 * *$ & $-0.44 * *$ & -0.11 & $-0.26^{*}$ & -0.05 \\
\hline Criticism Avoidance & $0.57 * *$ & $-0.49 * *$ & $-0.31 * *$ & $-0.33^{* *}$ & $-0.23 *$ \\
\hline Self-sacrifice & $0.27 * *$ & -0.07 & 0.05 & 0.10 & 0.02 \\
\hline Conscientiousness & -0.01 & 0.04 & 0.06 & 0.16 & $0.52 * *$ \\
\hline Impulsiveness & $0.37 * *$ & -0.05 & -0.05 & $-0.48 * *$ & $-0.33 * *$ \\
\hline
\end{tabular}


evidence of convergent-discriminant validity for this dimension, since there was convergence with a theoretically coherent facet (hostility) and divergence with others (facets of agreeableness).

Furthermore, the relationships found indicate that individuals with high scores on the aggressiveness dimension of IDCP tend to experience anger and not to be moved by the situation of others or to imagine themselves in other people's situations. Regarding the IDCP dimension of mood instability, most relations with the NEO-PI-R were with the facets of neuroticism dimension, in fact, with the six facets of this dimension. This relationship was expected since both the dimension of the NEO-PI-R (Costa \& McCrae Jr., 2009) and the IDCP are related to a propensity to sad and irritable mood, mood swing, impulsive responses, and in some cases, guilt.

The eccentricity dimension presented a relation (negative) higher than 0.40 only with the gregariousness facet. This relationship suggests validity for the IDCP dimension since the dimension of IDCP concerns, among other attributes, the absence of pleasure in being with others, and the facet of the NEO-PI-R is related to a preference for the company of people (Widiger, Trull, et al., 2002). Also the attention seeking dimension was related to the gregariousness facet, but, positively. The same occurred between this dimension and the assertiveness, positive emotionality, and feelings facets. These relationships suggest that people with high scores on the attention seeking dimension tend to prefer the company of people, present leadership and independency, experience positive emotions, and to be receptive about their own feelings (Widiger, Costa, et al., 2002). These relationships are consistent in so far as the dimension in IDCP is related to exaggerated attention seeking and intensive search for friendships.

Consistent relationships were also found between the distrust dimension and the hostility (positive) and confidence (negative) facets. This IDCP dimension deals with the persistent inability to trust people, while the facets of the NEO-PI-R (Widiger, Trull, et al., 2002) relate to the tendency to experience anger (hostility) and not to believe in people (low trust).

On the other hand, the grandiosity dimension presented higher relationships with three facets of the neuroticism dimension, and the relationship between this dimension and the hostility facet was already expected according to the data by Samuel and Widiger (2008). These relations indicate that people with exaggerated need for admiration and recognition tend also to present higher levels of anxiety, anger, and impulsive behaviors (Widiger \& Lowe, 2008). Still, relations between grandiosity and facets of agreeableness were all negative, as well as with the cordiality and gregariousness facets of the extraversion dimension, which is in line with the theoretical expectation suggesting the disregard towards the other (on behalf of an exaggerated focus on self) by individuals presenting characteristics related to the narcissistic functioning (prevalent in the grandiosity dimension, according to Table 1).

Regarding the isolation dimension, the main positive relationships evidenced were with depression and embarrassment facets and negative with warmth, gregariousness, and reliability. These data confer validity to the interpretation made for the isolation dimension, that is, individuals with little pleasure with relationships, avoiding social interaction, and with a preference for staying alone, since the most related facets of the NEO-PI-R have to do with trends towards sadness, loneliness, embarrassment in front of people, and in the negative pole (of the facets with negative relation), a trend to little affectivity and distrust (Samuel \& Widiger, 2008).

Similarly, the criticism avoidance dimension to the IDCP, characterized by individuals who believe they will be criticized and humiliated, presented a negative relationship with the facet confidence but also with gregariousness and warmth, which seems to be consistent according to the definitions already presented. Furthermore, this dimension correlates positively with most facets of the neuroticism dimension, indicating that these people have a tendency to display negative emotional states.

Conversely to the other dimensions of the IDCP, selfsacrifice showed no relation lower than 0.40 . Nevertheless, the highest ratio found, 0.37 , with the depression facet, indicates a significant relationship between this dimension and the trends towards sadness (Widiger, Costa, et al., 2002). This relation may be regarded as consistent as people with high scores in self-sacrifice tend to disregard themselves on behalf of a rather exaggerated consideration for others. Further, also the relation with the embarrassment facet has been observed, indicating that people with high scores in the self-sacrifice dimension tend to exhibit shame and embarrassment.

However, the conscientiousness dimension of the IDCP presented a positive and significant relationship with all facets of the conscientiousness dimension of NEO-PI-R, with the highest magnitudes evidenced by the sense of duty and concern facets. Considering the characteristics evaluated by the dimension of the IDCP, the relations found are consistent, since sense of duty relates to the fulfillment of moral obligations and concern relates to the tendency to think carefully before acting (Widiger, Trull, et al., 2002).

Finally, the impulsiveness dimension of the IDCP showed a positive relation with the impulsiveness facet of the NEOPI-R and a negative relation with the complacency and concern facets. These relationships indicate discriminant validity for the interpretation of the IDCP's reactions of impulsiveness and recklessness with a taste for violent activities, since the facets concern the tendency not to resist to inner desires, and in the negative pole (of the facets with negative relationship), a tendency to show aggression and not to think carefully before acting.

Next, we proceeded to prototype matching analysis. Table 4 shows the correlations of the dimensions of IDCP with the similarity indices of profiles of subjects with diagnostic categories of the DSM-IV-TR (from the correlations of the profile on the NEO-PI-R with the prototypical profiles of disorders).

In general, there is an overall tendency for the correlations to be significant and positive, indicating that individuals with high scores on the IDCP tend to present similar profiles to those of personality disorders. Besides, it can be observed that the mood instability dimension was highly correlated to a great part (7) of the diagnostic categories suggesting that this 
dimension is related to a variety of extreme personality traits, similarly to the neuroticism dimension of the NEO-PI-R.

In contrast, none of the categories presented magnitude higher than or equal to 0.60 with the dimensions dependency eccentricity, suspiciousness, grandiosity, isolation, and selfsacrifice. Nevertheless, the dependency dimension showed higher relationships with the borderline, schizotypal, and dependent category; aggressiveness with narcissistic, antisocial, and paranoid; mood instability with paranoid, schizotypal, and borderline; eccentricity with schizotypal, paranoid, and schizoid; attention seeking with histrionic, narcissistic, and schizoid; distrust with paranoid, narcissistic, and schizotypal; grandiosity with paranoid, schizotypal, and narcissistic; isolation with schizoid, schizotypal, and paranoid; criticism avoidance with schizoid, paranoid, and schizotypal; self-sacrifice with schizotypal, avoidant, and schizoid; conscientiousness with obsessive, histrionic, and antisocial; and impulsiveness with antisocial, narcissistic, and borderline.

Although there is an underlying consistency to the key relationships evidenced, for some diagnostic categories the theoretically more consistent IDCP dimensions presented higher correlation magnitudes, but we observed some magnitudes that can impair the discriminant validity of certain dimensions (grandiosity, detachment, and criticism avoidance).

Table 3. Correlations between dimensions of IDCP and facets of NEO-PI-R

\begin{tabular}{|c|c|c|c|c|c|c|c|c|c|c|c|c|}
\hline & 1 & 2 & 3 & 4 & 5 & 6 & 7 & 8 & 9 & 10 & 11 & 12 \\
\hline Anx. & $0.33 * *$ & $0.23 *$ & $0.58 * *$ & 0.20 & 0.02 & $0.34 * *$ & $0.44 * *$ & $0.25^{*}$ & $0.45 * *$ & 0.19 & 0.04 & 0.20 \\
\hline Host. & $0.45 * *$ & $0.51 * *$ & $0.68 * *$ & $0.28 * *$ & 0.06 & $0.45 * *$ & $0.49 * *$ & $0.39 * *$ & $0.48 * *$ & 0.18 & -0.05 & $0.38 * *$ \\
\hline Depre. & $0.45 * *$ & $0.34 * *$ & $0.66^{* *}$ & $0.36^{* *}$ & -0.20 & $0.34 * *$ & $0.38 * *$ & $0.51 * *$ & $0.60 * *$ & $0.37 * *$ & 0.04 & $0.26^{*}$ \\
\hline Emb. & $0.37 * *$ & 0.09 & $0.56^{* *}$ & 0.20 & $-0.34 * *$ & $0.29 * *$ & $0.26^{*}$ & $0.42 * *$ & $0.33 * *$ & $0.31 * *$ & 0.15 & 0.05 \\
\hline Imp. & $0.32 * *$ & $0.38 * *$ & $0.53^{* *}$ & $0.22 *$ & 0.19 & $0.30 * *$ & $0.42 * *$ & $0.24 *$ & $0.26^{*}$ & 0.13 & -0.11 & $0.54 * *$ \\
\hline Vuln. & $0.43^{* *}$ & $0.21 *$ & $0.53 * *$ & 0.04 & -0.19 & 0.20 & $0.27 * *$ & $0.23 *$ & $0.40 * *$ & 0.01 & -0.12 & 0.19 \\
\hline Warm. & -0.13 & $-0.37 * *$ & $-0.45^{* *}$ & $-0.31 * *$ & $0.36^{* *}$ & $-0.35 * *$ & $-0.29 * *$ & $-0.51 * *$ & $-0.50 * *$ & -0.03 & -0.03 & $-0.21^{*}$ \\
\hline Greg. & -0.13 & $-0.25^{*}$ & $-0.40 * *$ & $-0.41 * *$ & $0.41^{* *}$ & $-0.33 * *$ & $-0.28 * *$ & $-0.61 * *$ & $-0.48 * *$ & -0.18 & -0.10 & -0.12 \\
\hline Ass. & -0.18 & 0.16 & -0.09 & 0.10 & $0.40 * *$ & 0.14 & 0.08 & -0.02 & -0.13 & 0.01 & 0.16 & -0.06 \\
\hline Ativ. & -0.10 & 0.02 & 0.02 & 0.01 & $0.25 *$ & 0.20 & 0.06 & -0.01 & -0.02 & 0.10 & $0.32 * *$ & 0.01 \\
\hline Enth. & 0.01 & 0.12 & -0.03 & 0.12 & $0.37 * *$ & 0.01 & 0.08 & -0.13 & -0.19 & -0.01 & -0.11 & $0.27 * *$ \\
\hline E. P. & -0.14 & -0.13 & $-0.31 * *$ & -0.07 & $0.42 * *$ & -0.15 & -0.13 & $-0.26^{*}$ & $-0.42 * *$ & -0.06 & 0.03 & 0.02 \\
\hline Fant. & 0.09 & 0.14 & 0.04 & 0.02 & $0.25^{*}$ & -0.05 & 0.12 & -0.13 & -0.14 & 0.01 & -0.11 & 0.17 \\
\hline Aesth. & 0.01 & $-0.23 *$ & 0.03 & 0.04 & 0.07 & 0.02 & 0.04 & 0.09 & -0.15 & -0.06 & 0.12 & $-0.26^{*}$ \\
\hline Feel. & 0.02 & -0.04 & 0.02 & -0.04 & $0.47 * *$ & 0.08 & -0.01 & -0.16 & $-0.27 * *$ & 0.09 & 0.04 & 0.05 \\
\hline Act. & $-0.31 * *$ & -0.13 & $-0.27 *$ & -0.11 & 0.19 & $-0.22 *$ & $-0.34 * *$ & $-0.29 * *$ & $-0.25^{*}$ & -0.04 & -0.18 & -0.06 \\
\hline Ide. & -0.09 & -0.12 & -0.07 & 0.18 & 0.10 & 0.05 & -0.07 & 0.05 & -0.17 & 0.03 & $0.28 * *$ & -0.15 \\
\hline Val. & -0.11 & -0.14 & -0.04 & 0.02 & $0.24 *$ & -0.03 & -0.10 & -0.01 & $-0.21 *$ & 0.15 & 0.01 & 0.09 \\
\hline Conf. & -0.17 & $-0.41 * *$ & $-0.52 * *$ & $-0.27^{*}$ & $0.23 *$ & $-0.47 * *$ & $-0.38 * *$ & $-0.47 * *$ & $-0.52 * *$ & -0.03 & 0.03 & $-0.37 * *$ \\
\hline Open. & -0.13 & $-0.49 * *$ & $-0.24 *$ & -0.19 & $-0.37 * *$ & $-0.23 *$ & $-0.32 * *$ & -0.11 & -0.15 & -0.01 & 0.08 & $-0.39 * *$ \\
\hline Altru. & -0.07 & $-0.48 * *$ & $-0.34 * *$ & $-0.29 * *$ & 0.09 & $-0.22 *$ & $-0.28 * *$ & $-0.30 * *$ & $-0.32 * *$ & 0.10 & 0.09 & $-0.32 * *$ \\
\hline Com. & $-0.30 * *$ & $-0.51 * *$ & $-0.44 * *$ & -0.11 & -0.12 & $-0.22 *$ & $-0.30 * *$ & $-0.29 * *$ & $-0.28 * *$ & -0.10 & 0.17 & $-0.46^{* *}$ \\
\hline Mod. & -0.21 & $-0.33 * *$ & -0.08 & 0.02 & $-0.37^{* *}$ & -0.13 & $-0.24 *$ & 0.12 & 0.05 & $0.25^{*}$ & 0.16 & -0.14 \\
\hline Sensi. & -0.04 & $-0.31 * *$ & -0.16 & -0.05 & -0.01 & -0.04 & -0.13 & -0.01 & -0.16 & 0.20 & 0.14 & $-0.31 * *$ \\
\hline Comp. & $-0.29 * *$ & -0.14 & $-0.24^{*}$ & -0.07 & $0.27^{* *}$ & 0.03 & 0.03 & -0.09 & -0.17 & -0.01 & $0.31 * *$ & -0.20 \\
\hline Ord. & -0.08 & -0.02 & -0.10 & 0.01 & $0.24 *$ & 0.01 & 0.06 & 0.04 & -0.09 & 0.04 & $0.32 * *$ & -0.10 \\
\hline S. D. & -0.07 & $-0.25^{*}$ & -0.18 & 0.12 & 0.02 & 0.08 & -0.08 & 0.05 & -0.16 & 0.14 & $0.45^{* *}$ & $-0.34 * *$ \\
\hline E. A. & -0.14 & -0.01 & -0.10 & 0.03 & $0.24^{*}$ & 0.13 & 0.06 & 0.04 & -0.09 & 0.09 & $0.34 * *$ & -0.04 \\
\hline S-d. & $-0.41 * *$ & -0.17 & $-0.34 * *$ & -0.05 & 0.17 & -0.08 & -0.08 & -0.14 & $-0.22 *$ & -0.03 & $0.32 * *$ & $-0.21 *$ \\
\hline Conc. & $-0.29 * *$ & $-0.36 * *$ & $-0.39 * *$ & -0.16 & -0.18 & -0.14 & $-0.31 * *$ & -0.06 & $-0.22 *$ & -0.12 & $0.44 * *$ & $-0.48 * *$ \\
\hline
\end{tabular}

Note. Some facets of the NEO-PI-R presented internal consistency ranging from 0.40 and 0.69 , which can have as a consequence a decrease in the correlation magnitudes between these sets of items and the dimensions of the IDCP. Legend: $1=$ Dependency; $2=$ Aggressiveness; $3=$ Mood instability; 4= Eccentricity; 5= Attention Seeking; $6=$ Distrust; $7=$ Grandiosity; 8= Isolation; 9= Criticism avoidance; 10= Self-sacrifice; $11=$ Conscientiousness; 12= Impulsiveness; Anx.= Anxiety; Host.= Hostility; Depre.= Depression; Emb.= Embarrassment; Imp.= Impulsiveness; Vuln.= Vulnerability; Warm.= Warmth; Greg.= Gregariousness; Ass.=Assertiveness; Activ.=Activity; Enth.= Enthusiasm; P. E.= Positive Emotionality; Fant.= Fantasy; Aesth.= Aesthetics; Feel.= Feelings; Act.= Actions; Ide.= Ideas; Val.= Values; Conf.= Confidence; Open.= Openness; Altru.= Altruism; Com.= Complacency; Mod.= Modesty; Sensi.=Sensitivity; Comp.= Competence; Ord.= Order; S. D.= Sense of Duty; E. A.= Effort for achievements; S-d.= Self-discipline; Conc. $=$ Concern 
Furthermore, we emphasize the relationships observed between the paranoid, schizoid, schizotypal, and avoidant categories with the criticism avoidance dimension, which was expected since this dimension is related to difficulty relating to people (despite the presence of interest). The relationships found between aggression and impulsiveness with the antisocial category, between attention seeking and the histrionic category, and between the consciousness dimension and the obsessive category were also expected.

\section{Final Considerations}

This research has two broad objectives: to seek evidence of validity for the IDCP based on the FFM and to demonstrate the administration of the procedure of prototype matching analysis. Regarding the first, we consider that the results were positive, i.e., they confer validity evidence for the interpretations to the dimensions of IDCP from the scores of the respondents to the instrument. In this sense, we observed, on the one hand, clear relationships between dimensions of the IDCP and the NEO-PI-R, and on the other, that the dimensions of the IDCP are more closely related to certain facets of the different dimensions of the NEO-PI-R.

Regarding the second objective of this study, we expect that the application of the procedure herein called prototype matching analysis may contribute to studies of other researchers on various fields of mental health, since the application of this statistical procedure can be extended to several areas in this field. It should be considered that the prototype matching analysis allowed the searching for evidence and validity for the dimensions of the IDCP based on prototypes of the diagnostic categories of personality disorders grounded on the FFM.

Moreover, this analysis can be considered as a preliminary study in the field of validity evidence based on external criteria for the dimensions of the IDCP. Whereas the instrument consists of 12 dimensions, there is a need for consistent implementation of a series of studies to verify the adequacy of the interpretations carried out with these dimensions. For instance, it is important that the relationships between the dimensions of the IDCP and the 30 facets of the NEO-PI-R be increased and, therefore, it is likely that the use of other instruments based on the FFM will be needed.

As important limitations of this study we highlight the limited number of participants, and the prevalence of individuals without a diagnosis of personality disorder. Therefore, we emphasize the importance of conducting studies with the IDCP that perform data collections also in psychiatric samples. Furthermore, we must consider that the instrument used as a criterion (NEO-PI-R) is based on the dimensional model and relies on self-report. Upcoming studies should seek evidence for the dimensions of the IDCP through instruments that access personality information in different ways, and not only through self-report.

\section{References}

American Psychiatry Association. (2003). Manual diagnóstico e estatístico de transtornos mentais DSM-IV-TR (4⿳亠丷厂 ed.). Porto Alegre: Artmed.

American Psychiatry Association. (2013). Diagnostic and statistical manual of mental disorders 5. Washington: American Psychiatry Association.

\begin{tabular}{|c|c|c|c|c|c|c|c|c|c|}
\hline 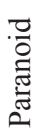 & 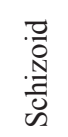 & 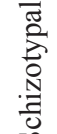 & 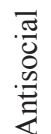 & 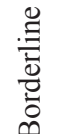 & 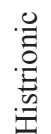 & $\begin{array}{l}\vec{n} \\
\cdot \frac{n}{n} \\
\frac{n}{0} \\
\vdots \\
Z\end{array}$ & 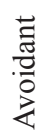 & 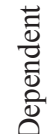 & 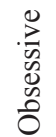 \\
\hline
\end{tabular}

\begin{tabular}{|c|c|c|c|c|c|c|c|c|c|c|}
\hline Dependency & $0.50 * *$ & $0.40 * *$ & $0.52 * *$ & $0.44 * *$ & $0.54 * *$ & 0.04 & $0.33 * *$ & $0.47 * *$ & $0.51 * *$ & -0.02 \\
\hline Aggressiveness & $0.58 * *$ & $0.38^{* *}$ & $0.51^{* *}$ & $0.62 * *$ & $0.54 * *$ & $0.21 *$ & $0.66^{* *}$ & $0.35 * *$ & $0.30 * *$ & 0.05 \\
\hline Mood Instability & $0.77 * *$ & $0.68 * *$ & $0.75 * *$ & $0.61 * *$ & $0.74 * *$ & -0.08 & $0.52 * *$ & $0.67 * *$ & $0.61 * *$ & $0.21 *$ \\
\hline Eccentricity & $0.40 * *$ & $0.39 * *$ & $0.40 * *$ & $0.33 * *$ & $0.35 * *$ & -0.07 & $0.31 * *$ & $0.32 * *$ & $0.22 *$ & 0.15 \\
\hline Attention Seeking & -0.14 & $-0.40 * *$ & $-0.22 *$ & $0.21 *$ & -0.12 & $0.62 * *$ & $0.40 * *$ & $-0.38 * *$ & $-0.32 * *$ & $-0.27 *$ \\
\hline Distrust & $0.45^{* *}$ & $0.36^{* *}$ & $0.41 * *$ & $0.34 * *$ & $0.38 * *$ & -0.00 & $0.41 * *$ & $0.32 * *$ & $0.23 *$ & $0.28 * *$ \\
\hline Grandiosity & $0.56^{* *}$ & $0.43 * *$ & $0.51 * *$ & $0.48 * *$ & $0.50 * *$ & 0.06 & $0.52 * *$ & $0.41 * *$ & $0.35^{* *}$ & $0.21 *$ \\
\hline Isolation & $0.51 * *$ & $0.58 * *$ & $0.53 * *$ & $0.25^{*}$ & $0.44 * *$ & $-0.34 * *$ & 0.20 & $0.51 * *$ & $0.38 * *$ & $0.38 * *$ \\
\hline Criticism Avoidance & $0.63 * *$ & $0.65 * *$ & $0.63 * *$ & $0.38 * *$ & $0.58 * *$ & $-0.26^{*}$ & $0.27 * *$ & $0.62 * *$ & $0.53 * *$ & $0.29 * *$ \\
\hline Self-sacrifice & $0.26^{*}$ & $0.27 * *$ & $0.28 * *$ & 0.17 & $0.26^{* *}$ & -0.11 & 0.05 & $0.28 * *$ & $0.25 *$ & 0.07 \\
\hline Consciousness & 0.03 & 0.10 & -0.00 & $-0.21 *$ & -0.09 & $-0.26^{*}$ & -0.05 & 0.03 & -0.08 & $0.49 * *$ \\
\hline Impulsiveness & $0.44 * *$ & $0.24 *$ & $0.40 * *$ & $0.62 * *$ & $0.47 * *$ & $0.30 * *$ & $0.54 * *$ & $0.26^{*}$ & $0.26^{* *}$ & -0.19 \\
\hline
\end{tabular}

Notes. ${ }^{*}$ significant correlation magnitudes at $0.05 ; * *$ Significant correlation magnitudes at 0.01 
Carvalho, L. F. (2011). Desenvolvimento e verificação das propriedades psicométricas do inventário dimensional clínico da personalidade (Unpublished doctor dissertation), Programa de Pós-Graduação Stricto Sensu em Psicologia, Universidade São Francisco, Itatiba, SP, Brasil.

Carvalho, L. F., \& Primi, R. (2011). Inventário Dimensional Clínico da Personalidade (Manual Técnico não publicado), Universidade São Francisco, Itatiba, SP, Brasil.

Costa, P.T. Jr., \& McCrae, R.R. (1992). Revised NEO Personality Inventory (NEO-PI-R) and NEO Five-Factor Inventory (NEO-FFI) manual. Odessa, FL: Psychological Assessment Resources.

Costa Jr., P. T., \& McCrae, R. R. (2009). NEO-PI-R - Inventário de Personalidade NEO Revisado - Manual. São Paulo: Vetor.

Krueger, R. F., \& Eaton, N. R. (2010). Personality traits and the classification of mental disorders: Toward a complete integration in DSM-V and an empirical model of psychopathology. Personality Disorders: Theory, Research, and Treatment, 1, 97-118.

Millon, T., \& Davis, R. D. (1996). Disorders of personality DSM-IV and beyond. New Jersey: Wiley.

Millon, T., \& Grossman, S. (2007a). Moderating severe personality disorders. New Jersey: John Wiley \& Sons Inc..

Millon, T., \& Grossman, S. (2007b). Overcoming resistant personality disorders. New Jersey: John Wiley \& Sons Inc..

Mullins-Sweatt, S. N., Jamerson, J. E., Samuel, D. B., Olson, D. R., \& Widiger, T. A. (2006). Psychometric properties of an abbreviated instrument of the five-factor model. Assessment, 13, 119-137.

Ortigo, K. M., Bradley, B., \& Westen, D. (2010). An empirically based prototype diagnostic systems for DSM-V and ICD-11. In T. Millon, R. F. Krueger, \& E. Simonsen (Eds.), Contemporary directions in psychopathology: Scientific foundations of the DSM-V and ICD-11 (pp. 374-390). New York: Guilford Press.

Pilkonis, P. A., Hallquist, M. N., Morse, J. Q., \& Stepp, S. D. (2011). Striking the (im)proper balance between scientific advances and clinical utility: Commentary on the DSM 5 proposal for personality disorders. Personality Disorders: Theory, Research, and Treatment, 2(1), 68-82.

Primi, R. (2010). Avaliação psicológica no Brasil: Fundamentos, situação atual e direções para o futuro. Psicologia: Teoria e Pesquisa, 26(especial), 25-35.

Rottman, B. M., Ahn, W. K., Sanislow, C. A., \& Kim, N. S. (2009). Can clinicians recognize DSM-IV personality disorders from five-factor model descriptions of patient cases? American Journal of Psychiatry, 166, 427-433.
Samuel, D. B., \& Widiger, T. A. (2008). A meta-analytic review of the relationships between the five-factor model and DSMIV-TR personality disorders: A facet level analysis. Clinical Psychology Review, 28(8),1326-42.

Schroeder, M. L., Wormworth, J. A., \& Livesley, W. J. (1992). Dimensions of personality disorder and their relationships to the Big Five dimensions of personality. Psychological Assessment, 4(1), 47-53.

Skodol, A. E., Bender, D. S., Oldham, J. M., Clark, L. A., Morey, L. C., Verheul, R.,... Siever, L. J. (2011). Proposed changes in personality and personality disorder assessment and diagnosis for DSM-5, Part II: Clinical application. Personality Disorders: Theory, Research, and Treatment, 2, 23-40.

Skodol A. E., Bender D. S., Morey L. C., Clark L. A., Oldham J. M., Alarcon R. D., Krueger R. F., Verheul R., Bell C. C., Siever L.J. (2011). Personality Disorder Types Proposed for DSM 5. Journal of Personality Disorders, 25(2), 136-169.

Skodol, A. E., Clark, L. A., Bender, D. S., Krueger, R. F., Livesley, W. J., Morey, L. C.,... Oldham, J. M. (2011). Proposed changes in personality and personality disorder assessment and diagnosis for DSM-5, Part I: Description and rationale. Personality Disorders: Theory, Research, and Treatment, 2, 4-22.

Widiger T. A. (2011). A shaky future for personality disorders. Personality Disorders: Theory, Research, and Treatment, 2(1), 54-67.

Widiger, T. A., Costa, P. T., \& McCrae, R. R. (2002). A proposal for Axis II: Diagnosing personality disorders using the five factor model. In P. T. Costa \& T. A. Widiger (Eds.), Personality disorders and the five factor model of personality (2nd ed., pp. 431-456).Washington, DC: American Psychological Association

Widiger, T. A., \& Frances, A. J. (2002). Toward a dimensional model for the personality disorders. In P. T. Costa \& T. A. Widiger (Eds.). Personality disorders and the Five-Factor Model of Personality (2a ed., pp. 23-44). Washington, DC: American Psychological Association.

Widiger, T. A., \& Lowe, J. R. (2008). A dimensional model of personality disorder: Proposal for DSM-V. The Psychiatric Clinics of North America, 31(3), 363-78.

Widiger, T. A., \& Trull, T. J. (2007). Place tectonics in the classification of personality disorder: Shifting to a dimensional model. American Psychologist, 62(2), 71-83.

Widiger, T. A., Trull, T. J., Clarkin, J. F., Sanderson, C., \& Costa, P. T. (2002). A description of the DSM-IV personality disorders with the five-factor model of personality. In P. T. Costa \& T. A. Widiger (Eds.), Personality disorders and the Five-Factor Model of Personality (2nd ed., pp. 89-102). Washington, DC: American Psychological Association. 